\title{
First-in-man intravascular ultrasound guidance of percutaneous pulmonary valve implantation
}

\author{
Łukasz Kalińczuk, Katarzyna Biernacka, Witold Rużyłło, Marcin Demkow \\ Institute of Cardiology, Warsaw, Poland
}

\begin{abstract}
A 25-year-old male with dextro-transposition of the great arteries underwent a Rastelli procedure at the age of four. Nineteen years later, he underwent surgical pulmonary homograft replacement $(\varnothing 25-\mathrm{mm})$ plus proximal insertion of a $\varnothing 26-\mathrm{mm}$ conduit. One year later, echocardiography showed distal pulmonary homograft stenosis with normal pulmonary valve function. A bare-metal 36-mm stent (Ev3 IntraStent LD Max, Plymouth, MN, USA)was deployed (@6 atm) on a $24-\mathrm{mm}$ balloon-in-balloon catheter (BIB, NuMED, Hopkinton, NY, USA) at the distal anastomosis site and post-dilated (@8-atm)with an 16-mm ultra-high-pressure balloon (Mullin- $\mathrm{X}^{\mathrm{TM}}$, NuMED, Hopkinton). Right ventricle pressure remained $84 / 0-21 \mathrm{mmHg}$ with an angiographic $34 \%$ diameter stenosis (DS) at the proximal stent margin (Fig. 1A). Computed tomography revealed the homograft minimal lumen site dimensions of $7.2 \times 15.4-\mathrm{mm}$ ( $65 \% \mathrm{DS})$, identified at the proximal stent edge near the pulmonary annulus (Fig. 1B).
\end{abstract}

The homograft outer diameters were of $18.9 \times 23.7-$ -mm (Fig. 1B). Intravascular ultrasound (IVUS) with Visions ${ }^{\circledast}$ PV.035 Digital Catheter (Philips) revealed corresponding minimal lumen cross-sectional area (MLA) of $0.97-\mathrm{cm}^{2}(11.5 \times 12.3-\mathrm{mm})$ with homograft outer dimension of $17.9 \times 24.9-\mathrm{mm}$ (Fig. $1 \mathrm{C}$ ). The Melody $^{\mathrm{TM}}$ transcatheter pulmonary valve (Medtronic, Minneapolis, Minnesota, USA) was deployed on a 22-mm balloon after landing-zone pre-stenting with IntraStent on 20-mm BIB (overlapping the first stent distal margin). Despite a good angiographic result (Fig. 1D), IVUS MLA was $1.58-\mathrm{cm}^{2}(15.0 \times$ $\times 15.6-\mathrm{mm})$; thus, it was post-dilated using a $20-\mathrm{mm}$ (@6-atm) and 22-mm Mullins- $\mathrm{X}^{\mathrm{TM}}$ balloon (@11-atm). Final MLA was of $3.16-\mathrm{cm}^{2}(19.5 \times 20.2-\mathrm{mm}$; $0 \%$ DS), with a substantial increase in total homograft dimension and right ventricle pressure drop to $37 / 0-4 \mathrm{mmHg}$ (Fig. 1E).

The study complied with the Declaration of Helsinki, the patient signed informed consent, and the study was approved by the local ethics committee.

Funding: This work was supported by a research grant $(2.4 / \mathrm{VI} / 18)$ founded by the Institute of Cardiology in Warsaw (Poland).

Conflict of interest: Marcin Demkow is proctoring for Medtronic. All the other authors have no conflicts of interest with regard to this manuscript.

Address for correspondence: Łukasz Kalińczuk, MD, PhD, Institute of Cardiology, ul. Alpejska 42, 04-628 Warszawa, Poland, tel/fax: +48505 794691/+48 223434 528, e-mail: lukasz.kalinczuk@gmail.com

Received: 22.01.2020 Accepted: 6.02.2020 


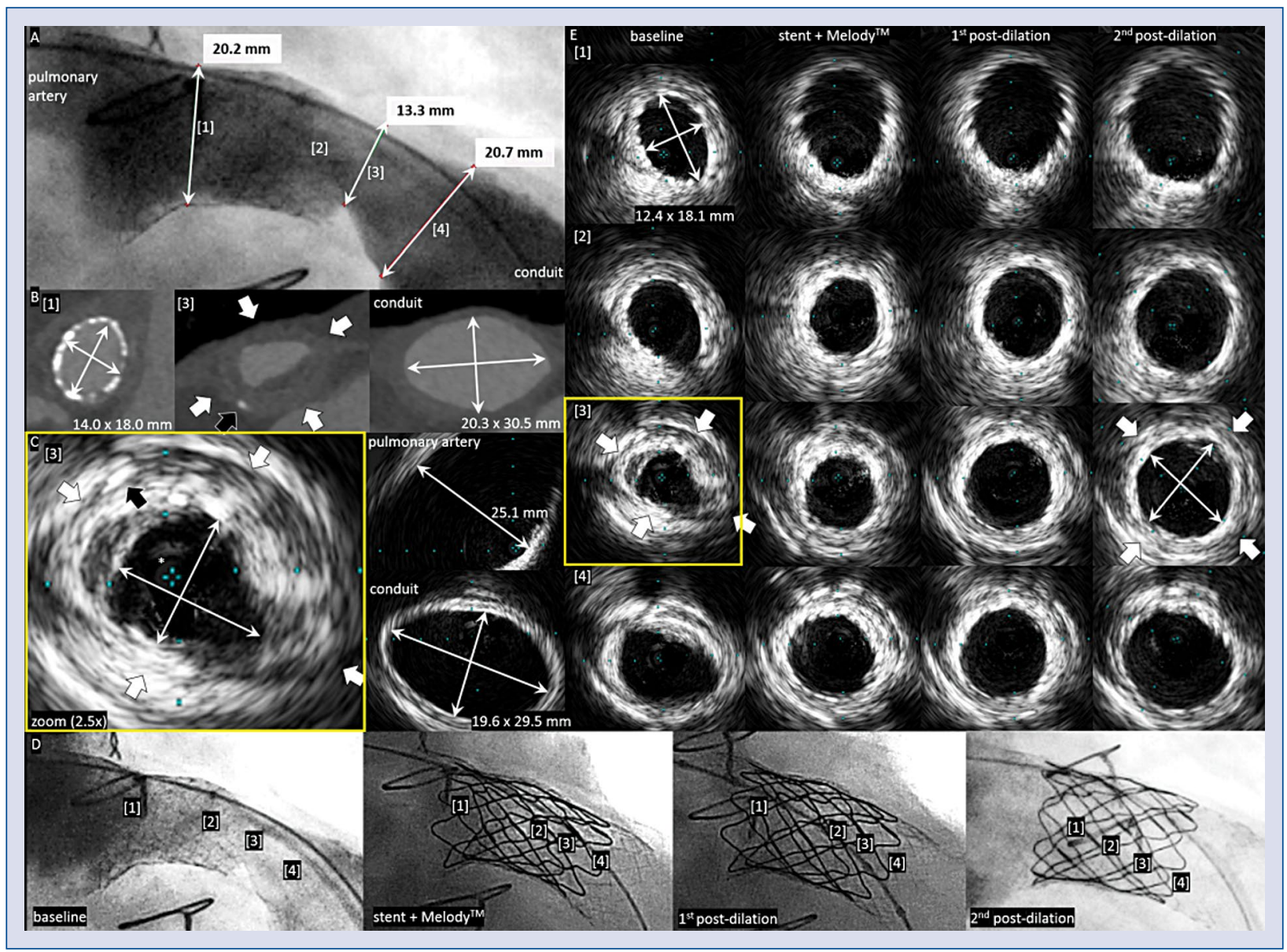

Figure 1. Corresponding angiography, computed tomography and intravascular ultrasound (IVUS) images; A. Angiography of the pulmonary homograft with indicated lumen diameters (white thin two-headed arrows) measured: distally [1]; at the minimal lumen site [3]; and proximally [4]; B. Computed tomography cross-sections perpendicular to the homograft long lumen axis obtained: distally (with indicated minimal and maximal in-stent diameters) [1]; at the site of homograft minimal lumen cross-sectional area (with its outer dimension marked with bold white arrows and a calcium deposit indicated with a black arrow) [3]; and within the conduit length (arrows indicate the relevant lumen diameters); C. IVUS recorded at the site of homograft minimal lumen cross-sectional area, with indicated minimal and maximal lumen diameters (white thin two-headed arrows) and its outer dimension (bold white arrows) [3]. The distal pulmonary artery and the conduit lumen diameters were also measured; D. Serial angiographies recorded at baseline, post pre-stenting and Melody ${ }^{\mathrm{TM}}$ deployment, and finally after the two sequential post-dilations; E. Serial IVUS images of the corresponding homograft sites, with measured: baseline minimal and maximal in-stent diameters (white thin two-headed arrows) distally [1]; the homograft outer dimensions assessed at the site of its minimal lumen cross-sectional area at baseline and post-procedure (bold white arrows) [3]; final in-valve minimal lumen cross-sectional area (white thin two-headed arrows) [3]. 